\title{
OUTCOME OF EARLY CLOSURE OF TEMPORARY STOMA
}

\author{
Muhammad Shahid Alam, ${ }^{1}$ Khalid Masood Gondal, ${ }^{2}$ Humayun Siddique, ${ }^{3}$ Yar Muhammad ${ }^{4}$
}

\begin{abstract}
Introduction: A stoma is a surgical procedure in which a part of gut is taken out and connected on the anterior abdominal wall. An anastomosis is the joining together of the two intestinal ends that remain after a diseased section has been removed. The closure of the stoma though thought to be minor surgical procedure, yet it may be associated with appreciable morbidity. When the reversal of stoma is done in less than 8 weeks following primary surgery then it is considered to be early closure. Early closure of the temporary stoma might reduce both stoma - related complications and patient ailment. Wound complications are common but there are many associated morbidities due to delay in closure. So the aim of this study is to find the complications associated with early closure of temporary
\end{abstract}

Alam M.S. ${ }^{1}$

Post Graduate Resident

North Surgical Ward, Mayo Hospital, Lahore

Gondal K.M. ${ }^{2}$

Chairman Department of Surgery

KEMU / Mayo Hospital, Lahore

Siddique $\mathrm{H}^{3}$

Senior Register

North Surgical Ward, Mayo Hospital, Lahore

Muhammad Y. ${ }^{4}$

Assistant Professor

North Surgical Ward, KEMU / Mayo Hospital, Lahore stoma.

Objective: To evaluate the outcome of early closure of temporary stoma.

Material and Methods: This descriptive case series study of 350 patients of both gender aged between $13-70$ years was conducted in surgical ward of mayo hospital, Lahore in one year duration from 01-01-2014 to 31-12-2014. The non-probability purposive sampling technique was used in this study. Written consent was obtained from the patients. Only the most senior consultants with 5 years' experience after post-graduation were the part of the team. Following admission they were advised distal loopogram to rule out any distal obstruction, leakage or any other pathology. Closure was performed and the evaluation of the patient and relevant investigations pertaining to diagnose complications like anastomotic leakage and wound complications was done. This was recorded daily for 5 days post-operatively in ward and then a follow up weekly for 1 month was performed. Analysis of data was done statistically using version 13.0. Mean \pm SD were calculated for age. Frequency and percentages were calculated for gender, anastomotic leakage and wound complications. Post-stratification chi-square test was applied keeping a $\mathrm{P}$-value $\leq 0.05$ as significant.

Results: In our study mean age of the patients was $42.73 \pm 13.68$ years, $60 \%$ patients were males whereas $40 \%$ patients were females. The study results showed that anastomotic leakage was found in $29(8.3 \%)$ patients and wound complication was found in $20.57 \%$ patients. Statistically insignificant difference was fou- 
nd between the wound complication and gender of the patients i.e. $\mathrm{p}$-value $=0.82$.

Conclusion: According to our study results the outcome of early closure of temporary stoma is a feasible and effective procedure with fewer complications.

Keywords: Early Closure, Temporary Stoma, Wound Complication, Anastomotic Leakage.

\section{Introduction}

A stoma is a surgical procedure in which a part of gut i.e. ileum or colon is brought outside the abdominal wall, connected and left open. It could be temporary or permanent depending upon whether reversible or not. Temporary stoma is also called as defunctioning or covering stoma which later on reversed back. The procedure is commonly used for management of many acquired and congenital conditions of the gastrointestinal tract. ${ }^{1}$

Since the formation of a stoma as a diverging procedure to allow time for healing of a pathological process distal to the exit of the proximal effluent, many concerns over the associated morbidity have been raised in literature. ${ }^{2}$ For indications like enteric perforation, tuberculous perforation, trauma (penetrating or blunt), rectal or colonic injury, distal repair or anastomosis after resection etc., the survival rate has dramatically improved. ${ }^{3}$

The closure of the stoma though thought to be minor surgical procedure, yet it may be associated with appreciable morbidity, such as anastomotic leakage / fistula, wound infection, dehiscence or incisional hernia. ${ }^{4}$ However there are queries regarding the timing of closure of these temporary stomas. ${ }^{5}$ Temporary stomas constructed are generally closed after 12 weeks, a period long enough to encounter stoma related complications, like nutritional imbalances, metabolic derangements, skin excoriation, stoma retraction, prolapse, ulcer, bleeding and stenosis. Also the condition like application and cost of stoma devices, social or psychological discrimination and lack of working ostomy associations severely affect the quality of life and increase the burden on health care budget. ${ }^{6}$ When the reversal of stoma is done in less than 8 weeks following primary surgery, it is called as early closure.

Temporary stoma early closure might reduce both patient discomfort and stoma - related morbidity. Feasibility of early closure of the temporary ileostomy after rectal surgery have been evaluated in two pros- pective non-randomized studies including $27^{7}$ and $39^{8}$ patients respectively. These pilot studies reported encouraging results, with no mortality and no need for revisional procedures. Samiullah et al conducted study at Saidu Teaching Hospital Swat; Pakistan from January 2007 to January 2010 concludes that temporary Ileostomy early closure reduces the chances of stoma related complications and is safe with low morbidity and minimal mortality.

Khan $\mathrm{N}$ et al conducted study at the Lady Reading Hospital, Peshawar Pakistan between Jan 2005 and Dec 2009 shows that in early closure anastomotic leak / fistula was $5.76 \%$, wound related complications $16.66 \%$. Thus the study states that following early closure of temporary stoma, frequency of complication is similar to late closure. Thus late closure of stoma should be abandoned. ${ }^{10}$

The study is thus to evaluate the outcome of early closure of temporary stoma so that the condition like lack of facilities and associated morbidities due to delayed closure can be controlled by early closure faciletating an improved effect on outcome of the primary disease and decreasing the burden on health care budget.

\section{Methodology}

This study was conducted on 350 patients in 4 surgical wards of Mayo Hospital, Lahore in 1 year duration from 1-01-2014 to 31-12-2014. It was a descriptive case series by design and patient selection was non probability purposive sampling. All patients both male and female of age $13-70$ years with temporary stoma presented during follow-up in outpatient department and previously admitted patients in ward who was subjected for early closure were included in the study. $\mathrm{Pt}$ with intestinal tuberculosis (on medical record), active infection (e.g. fever $>38 * \mathrm{~F}$, tachycardia, tachypnea, leukocytosis), sepsis or organ failure in the postoperative period and radiological signs of distal blockage and anastomotic leakage on distal loopogram were not included in the study.

Following admission distal loopogram to rule out any distal obstruction, leakage or any other pathology was done. All the routine investigations like $\mathrm{CBC}$, RFT's, serum electrolytes, blood sugar random, chest $\mathrm{X}$ ray, ECG was performed for fitness and rule out risk of surgery. Written consent was obtained from the patients. Only senior consultants with 5 years' experience after post-graduation were the part of the team. Clo- 
sure of the stoma was done under general anesthesia.

These patients were observed in the postoperative period under care of their respective attending surgeons. Patients were kept nil per mouth for 5 days after that sips followed by semisolid was started. The evaluation of the patient and relevant investigations pertaining to diagnose complications like anastomotic leakage and wound complications was done. This was recorded daily for 5 days post-operatively in ward and then a follow up weekly for 1 month was performed. Outcome variables i.e. anastomotic leakage was assessed by abdominal pain, tenderness and discharge of gut contents through wound and wound complications by red erythematous pussy discharge from wound with pain and tenderness or wound dehiscence i.e. ruptured of wound along surgical suture or opening wound spontaneously. All these variables were recorded in a predesigned proforma.

Statistical analysis of data was done using version 13.0. All data was recorded and analyzed. Variables included in the study were analyzed using the simple descriptive statistics. Mean \pm SD were calculated for age. Frequency and percentages were calculated for gender, anastomotic leakage and wound complications. Data was stratified for age, gender and duration of diabetes. Post-stratification chi-square test was applied keeping a P-value $\leq 0.05$ as significant.

\section{Results}

Total 350 cases participated in this study. The mean age of the patients was noted as $42.73 \pm 13.68$ years with minimum and maximum ages of 16 and 70 years respectively (Table 1 ).

Table 1: Descriptive statistics of age (years).

\begin{tabular}{|c|l|c|}
\hline \multirow{4}{*}{ Age (years) } & $\mathrm{n}$ & 350 \\
\cline { 2 - 3 } & Mean & 42.73 \\
\cline { 2 - 3 } & $\mathrm{SD}$ & 13.68 \\
\cline { 2 - 3 } & Minimum & 16.00 \\
\cline { 2 - 3 } & Maximum & 70.00 \\
\hline
\end{tabular}

In this study $60 \%$ patients were males whereas $40 \%$ patients were females. Anastomotic leakage was not found in $321(91.7 \%)$ patients while it was found in $29(8.3 \%)$ patients (Table 2$)$.
Table 2: Distribution about Anastomotic leakage.

\begin{tabular}{|c|l|c|c|}
\hline \multicolumn{2}{|c|}{} & Frequency & Percent \\
\hline \multirow{3}{*}{ Anastomotic leakage } & Yes & 29 & 8.3 \\
\cline { 2 - 4 } & No & 321 & 91.7 \\
\cline { 2 - 4 } & Total & 350 & 100.0 \\
\hline
\end{tabular}

Out of 29 patients with anastomotic leakage, 20 had age less than 50 years and 9 above 50 years. Statistically insignificant difference was observed between the age in categories and anastomotic leakage of the patients i.e. $p$-value $=0.955$ (Table 3 ) .

Table 3: Distribution about Anastomotic leakage in accordance with age (years).

\begin{tabular}{|l|l|r|r|r|}
\hline \multicolumn{2}{|c|}{} & \multicolumn{2}{|c|}{ Age (years) } & \multirow{2}{*}{ Total } \\
\cline { 3 - 5 } \multicolumn{2}{|c|}{} & $<50$ & $\geq 50$ & \\
\hline \multirow{2}{*}{$\begin{array}{l}\text { Anastomotic } \\
\text { leakage }\end{array}$} & No & 223 & 98 & 321 \\
\cline { 2 - 5 } & Yes & 20 & 9 & 29 \\
\hline Total & 243 & 107 & 350 \\
\hline
\end{tabular}

P-value $=0.955$ (Insignificant $)$

Out of 29 patients with anastomotic leakage, 10 were females and 19 males. Statistically insignificant difference was found between the anastomotic leakage and gender of the patients I.e. p-value $=0.56$ (Table 4).

Wound complication was found in 72 (20.57\%) patients whereas not found in $278(79.43 \%)$ patients (Fig. 1).

Table 4: Distribution about Anastomotic leakage in accordance with Gender.

\begin{tabular}{|l|l|c|c|c|}
\hline \multicolumn{2}{|c|}{} & \multicolumn{2}{c|}{ Gender } & \multirow{2}{*}{ Total } \\
\cline { 3 - 5 } \multicolumn{2}{|c|}{} & Female & Male & \\
\hline $\begin{array}{l}\text { Anastomotic } \\
\text { leakage }\end{array}$ & Yes & 10 & 19 & 29 \\
\cline { 2 - 5 } & No & 130 & 191 & 321 \\
\hline \multicolumn{2}{|l|}{ Total } & 140 & 210 & 350 \\
\hline
\end{tabular}

$\mathrm{P}$-value $=0.56($ Insignificant $)$ 


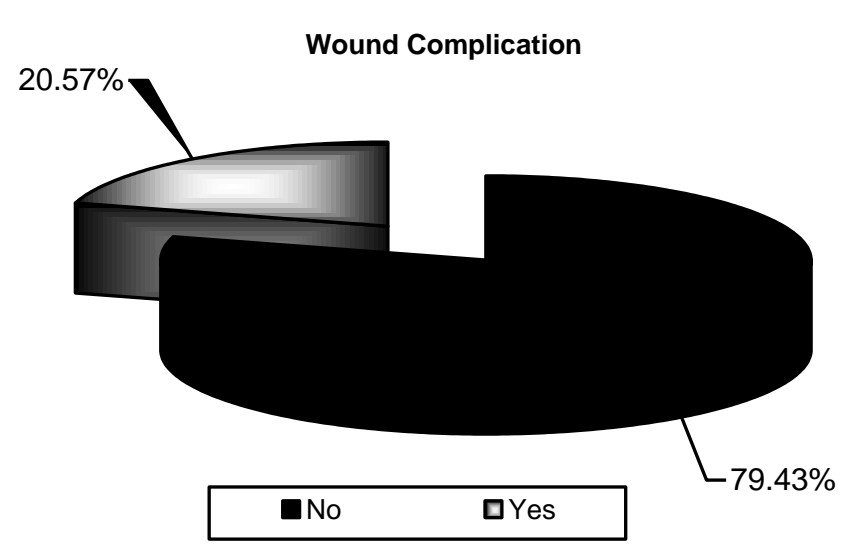

Fig. 1: Distribution about wound complication.

Out of 72 patients with wound complication, 51 had age less than 50 years and 21 above 50 years. Statistically insignificant difference was observed between the age in categories and wound complication of the patients i.e. $\mathrm{p}$-value $=0.88$ (Table 5$)$.

Table 5: Distribution about wound complication in accordance with age (years).

\begin{tabular}{|l|c|r|r|c|}
\hline \multicolumn{2}{|c|}{} & \multicolumn{2}{|c|}{ Age (years) } & \multirow{2}{*}{ Total } \\
\cline { 3 - 4 } \multicolumn{2}{|c|}{} & $<50$ & $\geq 50$ & \\
\hline $\begin{array}{l}\text { Wound } \\
\text { Complication }\end{array}$ & Yes & 51 & 21 & 72 \\
\cline { 2 - 5 } & No & 192 & 86 & 278 \\
\hline \multicolumn{2}{|l|}{ Total } & 243 & 107 & 350 \\
\hline
\end{tabular}

P-value $=0.88$ (Insignificant $)$

Out of 72 patients with wound complication, 28 were females and 44 males. Statistically insignificant difference was found between the wound complication and gender of the patients i.e. $p$-value $=0.82$ (Table 6 )

Table 6: Distribution about wound complication in accordance with Gender.

\begin{tabular}{|l|l|r|r|r|}
\hline \multicolumn{2}{|c|}{} & \multicolumn{2}{c|}{ Gender } & \multirow{2}{*}{ Total } \\
\cline { 3 - 5 } \multicolumn{2}{|c|}{} & Female & Male & \\
\hline \multirow{2}{*}{$\begin{array}{l}\text { Wound } \\
\text { complication }\end{array}$} & Yes & 28 & 44 & 72 \\
\cline { 2 - 5 } & No & 112 & 166 & 278 \\
\hline Total & 140 & 210 & 350 \\
\hline
\end{tabular}

P-value $=0.82$ (Insignificant)

\section{Discussion}

This descriptive case series was conducted in 4 surgical wards of mayo hospital, Lahore to determine the outcome of early closure of temporary stoma. Rectal anastomosis is frequently covered by constructing temporary ileostomy to avoid peritonitis due to anastomosis leakage. Several prospective studies and a single randomized controlled trial have shown that closure in less than two weeks was associated with lower or equal morbidity compared with later closure.

In our study early temporary stoma complications were observed (anastomotic leakage in $8.3 \%$ patients and wound complication were in $20.57 \%$ ). Other studies also support the results of our study.

A prospective uncontrolled Dutch study considered the possibility of returning the stoma after 11 days. ${ }^{11}$ A total of 18 patients had their stoma closed after $7-21$ days (the median was 11 days) and $22 \%$ of these had complications. A retrospective study from $2006^{12}$ showed that by returning the stoma after more than 60 days, the risk of complications decreased significantly.

Žukauskienè $\mathrm{v}$ et al, concluded in their study that overall complication rate was $33 \%$ (4 patients). One patient $(8.3 \%)$ had a bowel obstruction, which resolved after conservative treatment. One patient $(8.3 \%)$ developed enteric fistula to the ileostomy incision and wound infection was noted in two $(16.6 \%) .{ }^{13}$ Pakistan from January 2007 to January 2010 concludes that temporary Ileostomy early closure reduces the chances of stoma related complications and is safe with low morbidity and minimal mortality. ${ }^{9}$

Khan $\mathrm{N}$ et al conducted study at the Lady Reading Hospital, Peshawar Pakistan between Jan. 2005 and Dec. 2009 shows that in early closure anastomotic leak / fistula was $5.76 \%$, wound related complications $16.66 \%$. Thus the study states that following early closure of temporary stoma, frequency of complication is similar to late closure. Thus late closure of stoma should be abandoned. ${ }^{10}$

Alves et al, concluded in their study that in selected patients, early stoma closure is feasible with reduced hospital stay, bowel obstruction and medical complications, but a higher wound complication rate. ${ }^{14}$ According to two randomized trials, preoperative chemo-radiotherapy did not increase early postoperative mortality and morbidity significantly. In selected patients early stoma closure could be considered even following preoperative chemo radiotherapy. ${ }^{15,16}$

Pere Jordi-Galais et al demonstrated in their study 
that early closure of bowel stoma can be performed without major complications in elective patients. This procedure shortens hospital stay. ${ }^{17}$ One study showed that Temporary loop ileostomy is the stoma of choice for temporary fecal diversion as most of its complications are manageable conservatively. ${ }^{17}$

A randomized and controlled study of 186 patients with reversal of stoma 8-10 days after surgery compared with the standard procedure, where the stoma was reversed after 62-69 days. In this study, there were no significant differences in frequencies of complications ( $15 \%$ in both groups), but there were significant differences in types of complications, where significantly more wound complications were associated with early closure group, and significantly more cases of small - bowel obstruction in late closure group. ${ }^{14}$

Danielsen et al concluded in their study that reversal of a temporary ileostomy is generally associated with a low morbidity and mortality. However, complications may occur following ostomy reversal requiring reoperation with subsequent minor complications, in ranges from $4-5 \%$ to $30 \%$ and major complications varying from $0 \%$ to $7-9 \%$. $^{18}$

\section{Conclusion}

According to our study results the outcome of early closure of temporary stoma is a feasible and effective procedure with fewer complications.

\section{References}

1. Miyano G, Yanai T, Okazaki T, Kobayashi H, Lane G, Yamataka A. Laparoscopy - assisted stoma closure. J Laparoendosc Adv Surg Tech. 2007; 17 (3): 395-8.

2. Gooszen A, Geelkerken R, Hermans J, Lagaay M, Gooszen H. Temporary decompression after colorectal surgery: randomized comparison of loop ileostomy and loop colostomy. Br J Surg. 1998; 85 (1): 76-9.

3. Phang PT, Hain JM, Perez-Ramirez JJ, Madoff RD, Gemlo BT. Techniques and complications of ileostomy takedown. The Am J Surg. 1999; 177 (6): 463-6.

4. Berry D, Scholefield J. Closure of loop ileostomy. Br J surg. 1997; 84 (4): 524.

5. Festen C, Severijnen RS, Vd Staak FH. Early closure of enterostomy after exteriorization of the small intestine for abdominal catastrophies. J Pediatr Surg. 1987; 218 (2): 196.

6. O'Leary D, Fide C, Foy C, Lucarotti M. Quality of life after low anterior resection with total mesorectal excision and temporary loop ileostomy for rectal carcinoma. Br J Surg. 2001; 88 (9): 1216-20.

7. Bakx R, Busch O, Bemelman W, Veldink G, Slors J, Van Lanschot J. Morbidity of temporary loop ileostomies. Digest Surg. 2004; 21 (4): 277-81.

8. Menegaux F, Jordi - Galais P, Turrin N, Chigot JP. Closure of small bowel stomas on postoperative day 10 . Eur J Surg. 2002; 168 (12): 713-5.

9. Ali M, Rahman S, Khan A, Khalily Y. Evaluation of Early Closure of Ileostomy. Go J Med Sci. 2010; 8 (2).

10. Khan N, Bangash A, Hadi A, Ahmad M, Sadiq M. Is early closure of stoma warranted in the management of temporary loop ileostomy? J Postgrad Med Inst. 2011; 24 (4).

11. Kronborg O, Gastroenterologisk OUK. Behandling af cancer recti i Danmark 1994 - 1999. Ugeskr Læger. 2004; 166 (5): 368.

12. Perez RO, Gama AH, Seid VE. Loop ileostomy morbidity: timing of closure matters. Dis Colon Rectum. 2006; 49 (6): 1539-45.

13. Žukauskienè V, Samalavičius NE. Early loop ileostomy closure: should we do it routinely? Lietuvos Chirurgija. 2013; 12 (3): 152-155.

14. Alves A, Panis Y, Lelong B, Dousset B, Benoist S, Vicaut E. Randomized clinical trial of early versus delayed temporary stoma closure after proctectomy. Br J Surg 2008; 95 (6): 693-8.

15. Bosset J-F, Collette L, Calais G, Mineur L, Maingon P, Radosevic - Jelic L, et al. Chemotherapy with preoperative radiotherapy in rectal cancer. $\mathrm{N}$ Eng $\mathrm{J}$ Med. 2006; 355 (11): 1114-23.

16. Gérard J-P, Conroy T, Bonnetain F, Bouché O, Chapet $\mathrm{O}$, Closon - Dejardin M-T, et al. Preoperative radiotherapy with or without concurrent fluorouracil and leucovorin in $\mathrm{T}_{3-4}$ rectal cancers: results of FFCD 9203. J Clin Oncol. 2006; 24 (28): 4620-5.

17. Jordi-Galais $P$, Turrin N, Tresallet C, Nguyen-Thanh Q, Chigot J-P, Menegaux F. Early closure of temporary stoma of the small bowel. Gastroenterol Clin et biolog. 2003; 27 (8-9): 697-9.

18. Danielsen AK, Correa-Marinez A, Angenete E, Skullmann S, Haglind E, Rosenberg J. Early closure of temporary ileostomy - the EASY trial: protocol for a randomised controlled trial. Br Med J. 2011; 1 (1). 